\title{
Brazilian multicenter study on pegvisomant treatment in acromegaly
}

${ }^{1}$ Departamento de Medicina Interna, Serviço de Endocrinologia e Metabologia do Paraná (SEMPR), Hospital de Clínicas, Universidade Federal do Paraná (UFPR), Curitiba, PR, Brasil ${ }^{2}$ Departamento de

Neuroendocrinologia, Hospital Brigadeiro, São Paulo, SP, Brasil ${ }^{3}$ Departamento de Endocrinologia, Hospital de Clínicas, Universidade Federal de Pernambuco

(UFPE), Recife, PE, Brasil

${ }^{4}$ Faculdade de Ciências da Saúde, Universidade de Brasília (UnB), Brasília, DF, Brasil

${ }^{5}$ Laboratório de Endocrinologia, Departamento de Endocrinologia,

Universidade Federal de Minas Gera (UFMG), Belo Horizonte, MG, Brasil ${ }^{6}$ Unidade de Endocrinologia,

Hospital de Clínicas, Universidade

Federal do Rio Grande do Sul (UFRGS), Porto Alegre, RS, Brasil

7 Unidade de Neuroendocrinologia Divisão de Endocrinologia e Metabolismo, Escola Paulista de Medicina, Universidade Federal de São Paulo (EPM-Unifesp),

São Paulo, SP, Brasil

${ }^{8}$ Unidade Neuroendócrina, Divisão de Endocrinologia e Metabolismo, Hospital de Clínicas, Faculdade de Medicina da Universidade de São Paulo (FMUSP), São Paulo, SP, Brasil ${ }^{9}$ Divisão de Neurocirurgia Funcional, Instituto de Psiquiatria (IPq), Hospita de Clínicas, Faculdade de Medicina da Universidade de São Paulo (FMUSP), São Paulo, SP, Brasil

${ }^{10}$ Centro de Pesquisa em Neuroendocrinologia, Divisão de Endocrinologia, Hospital Universitár Clementino Fraga Filho, Universidad Federal do Rio de Janeiro (HUCFF-UFRJ); Divisão de Neuroendocrinologia, Instituto Estadual do Cérebro Paulo Niemeyer, Secretaria Estadual de Saúde, Rio de Janeiro, RJ, Brasil

Correspondence to:

Cesar L. Boguszewsk Departamento de Medicina Interna, Serviço de Endocrinologia e Metabologia do Paraná, Hospital de Clínicas, Universidade Federal

do Paraná

Curitiba, PR, Brasil

Av. Agostinho Leão Junior, 285

80030-110 - Curitiba, PR, Brasil

Received on Apr/7/2019

Accepted on May/13/2019

DOI: 10.20945/2359-3997000000159
Cesar L. Boguszewski ${ }^{1}$

https://orcid.org/0000-0001-7285-7941

Martha Katherine P. Huayllas ${ }^{2}$

https://orcid.org/0000-0002-1042-5083

Lucio Vilar ${ }^{3}$

https://orcid.org/0000-0003-4815-6963

Luciana Ansaneli Naves ${ }^{4}$

https://orcid.org/0000-0002-3363-3803

Antonio Ribeiro-Oliveira Junior ${ }^{5}$

https://orcid.org/0000-0002-6114-5786

Beatriz Santana Soares 5

https://orcid.org/0000-0002-5686-7899

Mauro Antonio Czepielewski ${ }^{6}$

https://orcid.org/0000-0001-5083-5776

sulio Abucham?

https://orcid.org/0000-0003-4804-1525

Silvia Regina Correa-Silva ${ }^{7}$

https://orcid.org/0000-0003-2405-0013

Marcello Delano Bronstein ${ }^{8}$

https://orcid.org/0000-0002-0113-5201

Raquel Soares Jallad ${ }^{8}$

https://orcid.org/0000-0003-0477-1892

Felipe Gaia Duarte 8

https://orcid.org/0000-0002-3495-1301

Nina Rosa Musolino 9

https://orcid.org/0000-0003-1562-4476

Leandro Kasuki10

https://orcid.org/0000-0003-1339-3192

Monica Roberto Gadelha ${ }^{10}$

https://orcid.org/0000-0002-9250-3558

\section{ABSTRACT}

Objective: Investigate the therapeutic response of acromegaly patients to pegvisomant (PEGV) in a real-life, Brazilian multicenter study. Subjects and methods: Characteristics of acromegaly patients treated with PEGV were reviewed at diagnosis, just before and during treatment. All patients with at least two IGF-I measurements on PEGV were included. Efficacy was defined as any normal IGF-I measurement during treatment. Safety data were reviewed. Predictors of response were determined by comparing controlled versus uncontrolled patients. Results: 109 patients [61 women; median age at diagnosis 34 years; $95.3 \%$ macroadenomas] from 10 Brazilian centers were studied. Previous treatment included surgery $(89 \%)$, radiotherapy $(34 \%)$, somatostatin receptor ligands $(99 \%)$, and cabergoline (67\%). Before PEGV, median levels of GH, IGF-I and IGF-I \% of upper limit of normal were $4.3 \mu \mathrm{g} / \mathrm{L}$, $613 \mathrm{ng} / \mathrm{mL}$, and $209 \%$, respectively. Pre-diabetes/diabetes was present in $48.6 \%$ and tumor remnant in $71 \%$ of patients. Initial dose was $10 \mathrm{mg} /$ day in all except 4 cases, maximum dose was $30 \mathrm{mg} /$ day, and median exposure time was 30.5 months. PEGV was used as monotherapy in $11 \%$ of cases. Normal IGF-I levels was obtained in $74.1 \%$ of patients. Glycemic control improved in $56.6 \%$ of patients with pre-diabetes/diabetes. Exposure time, pre-treatment GH and IGF-I levels were predictors of response. Tumor enlargement occurred in $6.5 \%$ and elevation of liver enzymes in $9.2 \%$. PEGV was discontinued in 6 patients and 3 deaths unrelated to the drug were reported. Conclusions: In a real-life scenario, PEGV is a highly effective and safe treatment for acromegaly patients not controlled with other therapies. Arch Endocrinol Metab. 2019;63(4):328-36

\section{Keywords}

Acromegaly; human growth hormone derivatives; pegvisomant; multicenter study 


\section{INTRODUCTION}

At target cells, two distinct receptor-binding sites of the GH molecule bind to the extracellular domains of two identical pre-dimerized growth hormone receptors (GHR) forming an active 2:1 complex. Activation of GHR triggers a cascade of intracellular signaling including the JAK-STAT pathway, which is a key mediator of many genomic actions of GH $(1,2)$. Pegvisomant (PEGV) is a genetically engineered analog of human GH with a single-amino-acid substitution at position 120 (glycine) of binding site 2 of the GH molecule that promotes GHR antagonism. Its molecular structure also comprises amino acid substitutions within GH binding site 1 and addition of polyethylene glycol moieties that increase the half-life and reduce the immunogenicity of the compound. When PEGV binds to the GHR, it inhibits IGF-I synthesis and release $(3,4)$.

The development of PEGV has opened a new perspective in acromegaly treatment $(3,4)$. Despite that many patients obtain biochemical control of the disease with surgery, radiotherapy and/or medical therapy with somatostatin receptor ligands (SRL) and/ or cabergoline, a significant proportion of acromegaly patients remain inadequately controlled and in need of additional treatment (5). Accordingly, PEGV was approved in Europe, USA and other countries around the world for the treatment of acromegaly in patients previously treated by surgery or radiotherapy and not controlled with maximum doses of SRLs $(4,6)$. In these cases, PEGV may be used as monotherapy or in combination therapy with SRL and/or cabergoline. In Brazil, PEGV was approved to be commercialized in 2005, but its therapeutic use is not included in the 2013 and 2018 reports on the Clinical Protocol and Therapeutic Guidelines for Acromegaly of the Ministry of Health, due to cost-effectiveness issues $(7,8)$. As a consequence, PEGV treatment in Brazil is not reimbursed and its use is limited and only possible through "judicialization" - legal cases brought by individuals claiming their constitutional rights using the judicial system, or exceptionally, by individual outof-pocket expenditures (9).

Sustained PEGV concentrations are crucial to its efficacy, since the drug is a reversible, competitive GHR antagonist (3). In the pivotal long-term clinical trials with PEGV, normalization of serum IGF-I was observed in up to $97 \%$ of patients treated with PEGV during 12 months with doses as high as $40 \mathrm{mg} /$ day $(10,11)$. However, efficacy has been lower in observational real- life studies, where high doses are rarely used, as the recommended dose range by the regulatory agencies is $10-30 \mathrm{mg}$ daily (4). A recent report from the ACROSTUDY, an observational registry intended to collect data on PEGV therapy, including 2,090 patients treated with PEGV up to 12 years in 15 countries, found that the percentage of patients with normal IGF-I levels increased from $53 \%$ at year 1 to $73 \%$ at year 10 , and not surprisingly, accompanied by an average daily dose increment from $12.8 \mathrm{mg}$ at year 1 to $18.9 \mathrm{mg}$ at year 10 (12). In the same report, serious adverse events related to the drug, as evaluated by the treating physicians, were described in $2.3 \%$ of the patients. Elevation of liver enzymes (ALT or AST) greater than three times in relation to pre-treatment levels was observed in 3\% of the cases. Most patients (72.2\%) had no change in tumor size relative to the previous scan, $16.8 \%$ had a decrease, $6.8 \%$ an increase and $4.3 \%$ had both (12).

The present real-life study was designed to obtain information on the Brazilian experience with PEGV treatment in acromegaly patients. We have collected clinical, laboratorial and radiological data from 10 reference centers specialized in the management of pituitary diseases from different regions of Brazil. The primary aim was to examine efficacy and safety of PEGV treatment, followed by identification of good predictors of therapeutic response.

\section{SUBJECTS AND METHODS}

This is a retrospective, multicenter, real-life study, involving acromegaly patients treated with PEGV in 10 pituitary reference centers in Brazil. Diagnosis of acromegaly was made according to clinical features and elevated and/or non-glucose-suppressible serum GH levels, associated with increased IGF-I levels adjusted for age (13). A GH-secreting pituitary adenoma was evidenced by imaging at diagnosis in all cases, and the tumors were classified as micro $(<\mathrm{lcm})$ or macroadenoma $(\geq 1 \mathrm{~cm})$ according to the largest diameter.

Clinical, laboratorial and radiological characteristics of the study group were reviewed at diagnosis (DIAGN), just before PEGV treatment (PEGV-OFF) and during PEGV treatment until the last visit available (PEGV-ON). Information was obtained regarding age, gender, $\mathrm{GH}$ and IGF-I levels, tumor size, previous and concomitant treatments, glucose homeostasis, initial and maximal PEGV dose, and duration of treatment. All patients with at least two IGF-I measurements during PEGV 
treatment were included. Since this was a real-life study, serum IGF-I levels were determined at local laboratories and the results were interpreted according to the ageadjusted reference range for each specific assay used at the different settings. To standardize the results, serum IGF-I levels were expressed as a percentage of the upper limit of the normal (\%ULN) reference range of each method. Indication and monitoring of PEGV treatment were carried out according to the treating physician's clinical judgment, but data on liver enzymes, glucose and glycated hemoglobin Alc (HbAlc) levels, and tumor growth during medical treatment were determined in a routine practice in all cases. The main indication to initiate PEGV was uncontrolled disease after surgery and maximum dose of first generation SRLs and cabergoline, with or without previous radiotherapy. In few cases, PEGV was initiated in patients participating in clinical trials or due to adverse events of other medications. Efficacy was defined as any IGF-I measurement within the normal reference range adjusted for age during PEGV treatment. Safety data, including adverse events and dropouts, were also reviewed. Predictors of response were evaluated by comparing results from controlled and uncontrolled patients.

\section{Statistical analysis}

For the descriptive analysis, categorical variables were expressed as the percentage and frequency, and the numerical variables were expressed as the median (minimum - maximum values) or mean $\pm \mathrm{SD}$, according to the distribution of the sample. The MannWhitney $U$ test was used to evaluate the differences between hormonal levels at diagnosis, before and after PEGV therapy, as well as in the comparison between controlled and uncontrolled groups of patients. Fisher's exact test was used to examine the association between categorical variables. The Spearman test was used for correlations. The difference was considered statistically significant when $\mathrm{p}<0.05$.

\section{RESULTS}

\section{Study population}

A total of 109 patients (61 women and 48 men) were included in the study (Table 1). At diagnosis, the median age was 34 years (range 12-82) and a GH-secreting macroadenoma was demonstrated in $103(95.4 \%)$ patients and a microadenoma in only 5 patients $(4.7 \%)$. In one case the information about tumor size was unavailable. Median GH levels were $24.2 \mu \mathrm{g} / \mathrm{L}(0.9-1136 \mu \mathrm{g} / \mathrm{L})$, median IGF-I levels were $1053 \mathrm{ng} / \mathrm{mL}(396-2376 \mu \mathrm{g} / \mathrm{L})$ and median IGF-I ULN were $327 \%(120-756 \%)$. The results of 27 patients from one single center have been previously published (14).

Table 1. Clinical, laboratorial and radiological characteristics of the study population at diagnosis and just before pegvisomant treatment (PEGV-OFF)

\begin{tabular}{|c|c|c|c|}
\hline & Total $(\mathrm{N}=109)$ & Women ( $\mathrm{N}=61$ ) & Men $(\mathrm{N}=48)$ \\
\hline \multicolumn{4}{|l|}{ At diagnosis } \\
\hline Age (yrs) & $34(12-82)$ & $37(12-82)$ & $34(12-63)$ \\
\hline Micro/Macroadenoma (n) & $5 / 103$ & $2 / 58$ & $3 / 45$ \\
\hline $\mathrm{GH}(\mu \mathrm{g} / \mathrm{L})$ & $24.2(0.9-1136)$ & $20.8(3.0-680)$ & $26.0(0.9-1136)$ \\
\hline IGF-I (ng/mL) & $1053(396-2376)$ & $910(396-2376)$ & $1190(409-2320)$ \\
\hline IGF-I (\%ULN) & $327(120-756)$ & $313(129-672)$ & $349(120-756)$ \\
\hline \multicolumn{4}{|l|}{ At PEGV-OFF } \\
\hline Previous surgery (\%) & $97(89)$ & $53(87)$ & $44(92)$ \\
\hline Previous radiotherapy (\%) & $37(34)$ & $21(34)$ & $16(33)$ \\
\hline Previous SRL (\%) & $108(99)$ & $60(98)$ & $48(100)$ \\
\hline Previous cabergoline (\%) & $73(67)$ & $39(64)$ & $34(71)$ \\
\hline Pre-diabetes/Diabetes (\%) & $53(49)$ & $33(54)$ & 20 (42) \\
\hline Tumour remnant (\%) & $77(71)$ & $39(64)$ & $38(79)$ \\
\hline GH $(\mu \mathrm{g} / \mathrm{L})$ & $4.3(0.71-209)$ & $4.0(0.72-209)$ & $4.7(0.71-101)$ \\
\hline IGF-I (ng/mL) & $613(262-1503)$ & $569(275-1503)$ & $650(262-1312)$ \\
\hline IGF-I (\%ULN) & $209(99-637)$ & $194(99-637)$ & $220(100-596)$ \\
\hline
\end{tabular}

Values are shown as median (min - max); \%ULN: \% upper limit of normal; SRL: somatostatin receptor ligands; no significant differences between men and women were observed. 
A total of $97(89 \%)$ patients were submitted to transsphenoidal surgery, $37(34 \%)$ patients were treated with radiotherapy and $73(67 \%)$ received cabergoline. All but one patient were medically treated with SRL prior to PEGV. Just before PEGV treatment (PEGVOFF), the median GH levels were $4.3 \mu \mathrm{g} / \mathrm{L}(0.71-$ $209 \mu \mathrm{g} / \mathrm{L})$, median IGF-I levels were $613 \mathrm{ng} / \mathrm{mL}(262$ - $1503 \mathrm{ng} / \mathrm{mL}$ ) and median IGF-I ULN were $209 \%$ $(99.7-637 \%)$. The only patient with an IGF-I ULN below $100 \%$ was a 15 -year-old girl with an IGF-I level of $843 \mathrm{ng} / \mathrm{mL}(\mathrm{ULN}=850 \mathrm{ng} / \mathrm{mL}$ ) and GH level of $2.2 \mu \mathrm{g} / \mathrm{L}$ after surgery, octreotide and cabergoline, who was still growing and complaining of severe joint pain. Pre-diabetes/diabetes were present in 53 (48.6\%) of the patients, and $77(71 \%)$ had a tumor remnant in the magnetic resonance imaging (MRI) (Table 1). There were no significant differences between men and women at diagnosis and at PEGV-OFF.

\section{Pegvisomant treatment (PEGV-ON)}

The initial dose of PEGV was $10 \mathrm{mg} /$ day in 105 patients. In the other 4 cases, initial dose was 15 $\mathrm{mg}, 20 \mathrm{mg}$ and in two cases $40 \mathrm{mg} /$ week in two applications $(5.7 \mathrm{mg} /$ day). In $12(11 \%)$ of the cases, PEGV was used as monotherapy in the whole period of observation, while it was associated with SRL in 92 and/or with cabergoline in 23 patients, at different periods of time throughout the treatment, following treating physician's judgement. The median duration of PEGV exposure was 30.5 months (2 - 124 months), with a median maximum dose of $10 \mathrm{mg} /$ day. The initial dose was maintained during the entire period of PEGV exposure in $58(53 \%)$ patients, it was increased to $15 \mathrm{mg} /$ day in $12(11 \%)$, to $20 \mathrm{mg} /$ day in $26(24 \%)$ and to $30 \mathrm{mg} /$ day in only $11(10.2 \%)$. None of the patients received daily dose of PEGV higher than $30 \mathrm{mg} /$ day (Table 2). No statistically significant differences between men and women were noted at PEGV-ON.

Normalization of serum IGF-I levels at any point during therapy was obtained in $80(74.1 \%)$ patients: $11(92 \%)$ in monotherapy and $69(71 \%)$ in combined treatment. The median maximum dose of PEGV in monotherapy was $15 \mathrm{mg} /$ day and in combined treatment was $10 \mathrm{mg} /$ day, but these values were not statistically different. Figure 1 shows individual IGF-I ULN values before and after PEGV treatment in the whole cohort. In the PEGV-ON period of the study, median IGF-I levels and IGF-I ULN were $206 \mathrm{ng} / \mathrm{mL}$ $(30-946)$ and $84.4 \%(12.6-253.3)$, respectively, values significantly lower in relation to PEGV-OFF values $(\mathrm{p}<0.00001 ;$ Figure 2$)$. There was no difference in the PEGV treatment outcomes comparing patients who were previously irradiated with those who were not. Normal IGF-I was observed in 26 of 37 patients $(70.3 \%)$ previously treated with radiotherapy and in 54 of 72 patients $(75 \%)$ not irradiated. Improvement of glycemic control determined by fasting glucose and HbAlc levels was documented in 30 of 53 patients (56.6\%) with pre-diabetes/diabetes at PEGVOFF period.

Table 2. Therapeutic approach and efficacy of pegvisomant (PEGV) treatment in Brazilian acromegaly patients

\begin{tabular}{|c|c|c|c|}
\hline & Total (N = 109) & Women $(\mathrm{N}=61)$ & Men $(\mathrm{N}=48)$ \\
\hline PEGV initial dose 10 mg/day (\%) & $105(96)$ & $58(95)$ & $47(98)$ \\
\hline \multicolumn{4}{|l|}{ PEGV maximum dose (mg/day) } \\
\hline $5,7(\%)$ & $2(1.8)$ & $2(3.3)$ & $0(0)$ \\
\hline $10(\%)$ & $58(53)$ & $36(59)$ & $22(45.8)$ \\
\hline $15(\%)$ & $12(11)$ & $5(8.2)$ & $7(14.6)$ \\
\hline $20(\%)$ & $26(24)$ & $13(21.3)$ & $13(27.1)$ \\
\hline $30(\%)$ & $11(10.2)$ & $5(8.2)$ & $6(12.5)$ \\
\hline PEGV monotherapy (\%) & $12(11)$ & $8(13.1)$ & $4(8.3)$ \\
\hline PEGV + SRL (\%) & $92(84.4)$ & $53(87)$ & $39(81.2)$ \\
\hline PEGV + cabergoline (\%) & $23(21)$ & $11(18)$ & $12(25)$ \\
\hline PEGV exposure (months) & $30.5(2-124)$ & $30.0(2-110)$ & $30.5(2-124)$ \\
\hline IGF-I (ng/mL) & $206(30-946)$ & $192(30-828)$ & $220(88-946)$ \\
\hline |GF-I (\%ULN) & $84.4(12.6-253.3)$ & $72.5(12.6-253.3)$ & $89.5(21.6-246)$ \\
\hline Normal IGF-I on PEGV (\%) & $80(74.1)$ & 44 (73.3) & $36(75.0)$ \\
\hline
\end{tabular}

Values are shown as median (min - max); \%ULN, \% upper limit of normal; SRL, somatostatin receptor ligands; no significant differences between men and women were observed. 
Tumor enlargement was described in $5(6.5 \%)$ of 77 patients with tumor remnant at PEGV-OFF. Only one of the 5 patients was in monotherapy, and in all cases it was observed in aggressive tumors and considered unrelated to PEGV treatment by the treating physician. Elevation of liver enzymes greater than 3 times in relation to pre-treatment levels occurred in $10(9.2 \%)$ patients, lipohypertrophy, pain at injection site and headache were reported by 5,3 and 2 patients, respectively (Table 3). Six women and no man discontinued PEGV treatment, and the causes were lipohypertrophy, pain at injection site, headache, elevation of liver enzymes,

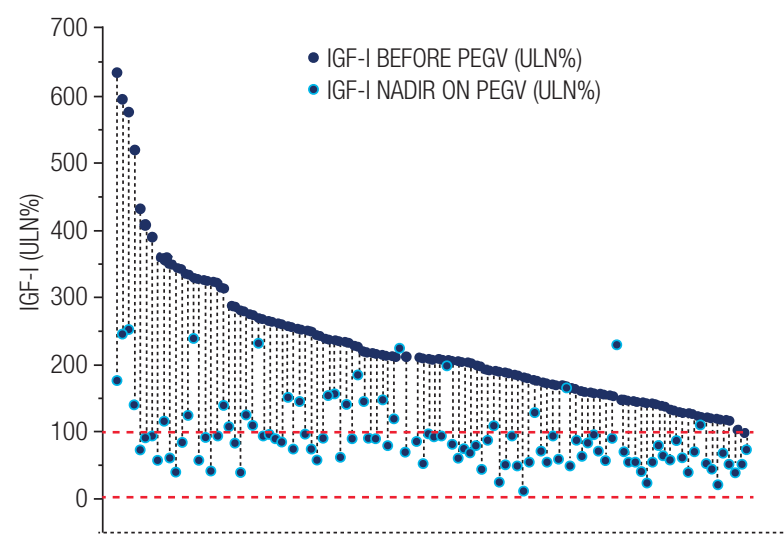

Figure 1. Individual IGF-I levels, expressed as a percentage of the age-adjusted upper limit of normal (ULN) range, before (dark blue circles) and after (light blue circles) pegvisomant (PEGV) treatment in 109 Brazilian patients with acromegaly.

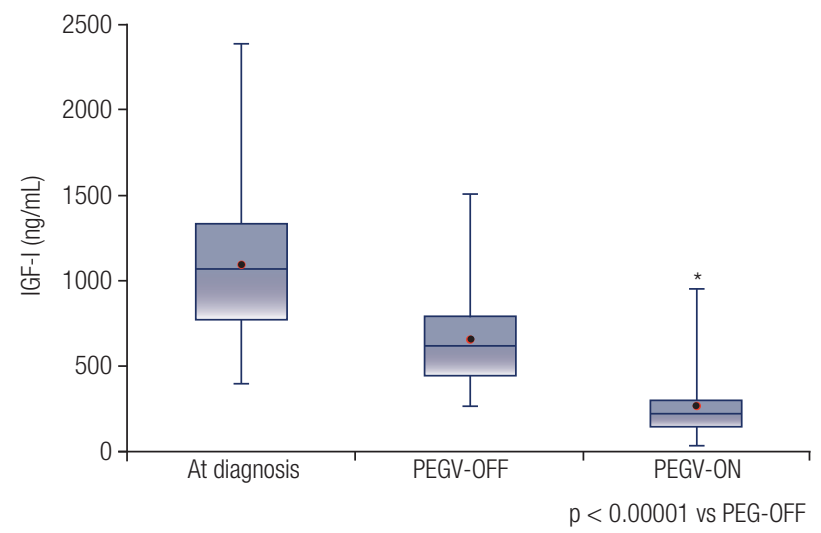

Figure 2. IGF-I levels at diagnosis, just before pegvisomant treatment (PEGV-OFF) and nadir values after pegvisomant treatment (PEGV-ON) in 109 Brazilian patients with acromegaly. Horizontal lines in the box plots represent from top to bottom: 97, 75, median, 25, and 3 percentiles, and the dots represent mean values.

Table 3. Safety data on pegvisomant treatment in Brazilian acromegaly patients

\begin{tabular}{lccc}
\hline & Total (N = 109) & Women (N = 61) & Men (N = 48) \\
\hline Tumour enlargement (\%)* & $5(6.5)$ & $5(12.8)$ & $0(0)$ \\
Elevation of liver enzymes (\%) & $10(9.2)$ & $5(8.2)$ & $5(10.4)$ \\
Lipohypertrophy (\%) & $5(4.6)$ & $4(6.5)$ & $1(2.1)$ \\
Pain at injection site (\%) & $3(2.7)$ & $3(4.9)$ & $0(0)$ \\
Headache (\%) & $2(1.8)$ & $2(3.3)$ & $0(0)$ \\
Treatment discontinuation (\%)* & $6(5.5)$ & $6(9.8)$ & $0(0)$ \\
Death (unrelated to therapy) (\%) & $3(2.7)$ & $2(3.3)$ & $1(2.1)$ \\
\hline
\end{tabular}

* In 77 patients with tumor remnant at beginning of treatment (39 women, 38 men).

\# Lipohypertrophy, pain at injection site, headache, elevation of liver enzymes, allergic reaction, pregnancy.

§ sudden death (unknown cause), stroke, severe heart failure. 
allergic reaction, and pregnancy. Three deaths were observed, all considered not related to PEGV therapy: a sudden death of unknown cause, one due to stroke and one caused by severe heart failure.

\section{Predictors of treatment response}

Table 4 shows the comparison of clinical and laboratorial characteristics at diagnosis and PEGV-OFF phases between patients controlled and uncontrolled at PEGV-ON. The median duration of PEG exposure was $41(2-120)$ months in the controlled group, which was significantly higher than $22(3-124)$ months observed in the uncontrolled group $(\mathrm{p}=0.03)$. At PEG-OFF, median GH levels were significantly lower in the controlled patients $[3.75 \mu \mathrm{g} / \mathrm{L}(0.71-101) v s$ $7.8 \mu \mathrm{g} / \mathrm{L}(1.03-209), \mathrm{p}<0.01)]$, as well as median IGF-I levels [570 ng/mL $(262-1155)$ vs $717 \mathrm{ng} / \mathrm{mL}$ $(279-1503), \mathrm{p}<0.001)]$ and IGF-I ULN [194\% (99 - 434) vs $241 \%(124-637), \mathrm{p}<0.001)]$. There was no difference between the two groups regarding age at diagnosis, gender, previous radiotherapy, and the presence of tumor remnant or pre-diabetes/diabetes.

\section{DISCUSSION}

This first Brazilian multicenter real-life study has confirmed the conclusion of previous clinical trials and observational studies that PEGV is an effective and safe medical therapy to acromegaly patients. In fact, PEGV might be the only therapeutic option to obtain biochemical control in a subgroup of patients who remain with active disease after surgery, radiotherapy, SRLs and cabergoline (15). Although the analysis of surveillance data suggests a biochemical control rate in approximately $75 \%$ of patients treated with PEGV as first-line monotherapy, PEGV is preferably a secondline medical therapy, as it has no effect on the GHsecreting adenoma $(13,15,16)$. This recommendation is in line with the Brazilian experience, as in our cohort $89 \%$ of patients were operated, all but one patient was treated with SRL, 67\% received cabergoline and roughly one-third was treated with radiotherapy before PEGV.

Acromegaly is associated with enhanced mortality and a high morbidity when normalization of $\mathrm{GH}$ and/or IGF-I levels is not achieved (17). There is some evidence that total direct treatment costs are higher for patients with uncontrolled compared to those with controlled disease (18). Thus, one should expect that a medication that promotes biochemical control rate in two-third of patients, as observed in our study, would result in a cost-effective treatment. However, our study was not designed to evaluate this outcome and there are still many unanswered questions about the benefits of controlled versus uncontrolled disease in relation to the economic impacts to health systems $(8,18)$.

The SRLs octreotide and lanreotide are the firstline medical therapy in most acromegaly patients, with biochemical control observed in $20-40 \%$ of patients, depending on the study design $(13,15,19-22)$. The new generation SRL pasireotide is effective in up to $20 \%$ of patients who do not respond to octreotide or lanreotide $(23,24)$. Our result of $74.1 \%$ of patients achieving normal IGF-I confirms that PEGV is one of the most effective drugs to obtain biochemical control in acromegaly. This percentage is slightly lower than that observed in a previous Brazilian single center study, in which $85 \%$ of 27 patients were successfully

Table 4. Comparison of clinical, laboratorial and radiological features between controlled (normal IGF-I levels on pegvisomant (PEGV-ON) and uncontrolled acromegaly patients

\begin{tabular}{lccc}
\hline & Controlled (N = 80) & Not controlled (N = 29) & P-value \\
\hline Age at diagnosis (yrs) & $35(12-75)$ & $31(12-82)$ & 0.09 \\
Female (\%) & $44(55)$ & $17(58.6)$ & 0.73 \\
Tumour Remnant (\%) & $55(68.7)$ & $22(78.6)$ & 0.32 \\
Previous radiotherapy (\%) & $26(32.5)$ & $11(37.9)$ & 0.59 \\
Pre-Diabetes/Diabetes (\%) & $36(45)$ & $17(58.6)$ & 0.20 \\
PEGV exposure (months) & $41(2-120)$ & $22(3-124)$ & 0.03 \\
GH PEGV-OFF ( $\mu$ gg/L) & $3.75(0.71-101)$ & $7.80(1.03-209)$ & 0.01 \\
IGF-I PEGV-OFF (ng/mL) & $570(262-1155)$ & $717(279-1503)$ & $<0.001$ \\
IGF-I PEGV-OFF (ULN\%) & $194(99-434)$ & $241(124-637)$ & $<0.001$ \\
\hline
\end{tabular}

PEGV-OFF: just before PEGV treatment; \%ULN: \% upper limit of normal. 
treated (14). In both studies the median daily dose of PEGV was $10 \mathrm{mg}$, and no patient received doses higher than $30 \mathrm{mg}$ after a median time of exposure of 30.5 months. The results from the single center and the present multicenter study in Brazil are surprisingly better than expected, as in the last report from the ACROSTUDY, an average dose of 12.8 mg was associated with normal IGF-I in $53 \%$ of the patients at year 1 (12). A percentage of $73 \%$ of normal IGF-I, similar to that of our study, was described in the ACROSTUDY only at year 10 with a higher average dose of $18.9 \mathrm{mg}$ (12). Besides the differences attributable to variable doses of PEGV in the studies, several other factors have been associated with the therapeutic responses to PEGV. Age, gender, body mass index, previous radiotherapy and the presence of diabetes have been suggested as predictive of the PEGV dose required for normalization of IGF-I levels (25-27). Height and weight were not available in our study, while age, gender, previous radiotherapy and diabetes were not correlated to PEGV dose and were not predictive of response to PEGV. On the other hand, we found that pre-treatment GH and IGF-I levels and time of exposure were predictors of response. In agreement, baseline GH and IGF-I levels have been correlated with the PEGV dose required to normalize serum IGF-I in patients with active acromegaly (28).

Another possible factor influencing the results of PEGV therapy in acromegaly among different studies is the number of patients in monotherapy and in combined therapy with SRLs and/or cabergoline. PEGV has shown efficacy rates as high as $97 \%$ when given in combination with an SRL and delivered once or twice weekly (29). In addition, effectiveness might continue after SRL discontinuation (30). This number is higher than that reported on long-term treatment with PEGV as monotherapy in the ACROSTUDY, where normal IGF-I was observed in $67.5 \%$ of patients at 5 years of therapy (31). In our study, PEGV was used as monotherapy in the whole period of observation in only $11 \%$ of the patients, while the vast majority of patients were also exposed to SRL at variable times during follow-up, and a smaller proportion was coexposed to cabergoline. These percentages are fairly similar to those of the Brazilian single center study (14), and might explain the good efficacy results observed in both real-life Brazilian studies, even that a large proportion of patients were treated with the lowest doses of PEGV. Accordingly, it has been previously demonstrated that the combined therapy of SRLs with PEGV can normalize IGF-I levels in virtually all patients and control tumor size in a vast majority of patients if an adequate dose of PEGV is used (32).

In our study, approximately $60 \%$ of patients treated with PEGV presented an improvement of their prediabetes/diabetes status, which is very relevant in comparison to other medications that are neutral or might even worsen glycemic control. A recent metaanalysis of prospective interventional studies have shown that PEGV, in monotherapy or combined with SRLs, improves glucose metabolism by reducing fasting plasma glucose and insulin levels, HbAlc, and insulin resistance, independently of disease control (33). In agreement with that, a consensus statement on acromegaly therapeutic outcomes has recommended PEGV as the best medical option for patients with impaired glucose tolerance unresponsive to firstgeneration of SRLs, due to its beneficial effect on insulin sensitivity and glucose tolerance (15).

The safety profile in our experience was fairly similar to what has been described in previous studies $(4,6)$. One of the major concerns related to PEGV therapy is the potential growth of the somatotroph pituitary adenoma due to reduced feedback mechanisms. Tumor enlargement was described in $3.2 \%$ out of 936 patients with a minimum of two available MRI examinations in a comprehensive review of 1288 subjects in ACROSTUDY (34). In the most recent ACROSTUDY report, $6.8 \%$ of 2090 patients had an increase in tumor size, very similar to our findings (12). In all of our cases, tumor growth was not considered as a consequence of PEGV treatment and occurred in patients harboring aggressive $\mathrm{GH}$-secreting adenomas unresponsive to multimodal therapies. It is possible that SRLs withdrawal might contribute to tumor growth in some cases, but it was not possible to evaluate the influence of SRLs withdrawal in our study due to its real-life design. Mild elevation of liver enzymes occurs in $9.2 \%$ of our cohort, as compared to $2.5 \%$ described in other studies (4), and it was a reason for PEGV discontinuation in one female patient. In the other cases, liver enzymes returned to normal upon temporary drug discontinuation, dose reduction or without intervention. There were other five dropouts, all in women, due to lipohypertrophy, pain, headache, allergic reaction, and pregnancy. There were also three deaths during follow-up that were considered unrelated to PEGV therapy by the treating physicians. 
In summary, PEGV treatment has been proved to be highly effective and safe in a large cohort of Brazilian patients with active acromegaly and not controlled with all other available therapeutic modalities. It might be particularly useful in patients with impaired glucose tolerance. In our study, lower pre-treatment GH and IGF-I levels and longer time of exposure were associated with better response to PEGV therapy.

Disclosures: CLB has received speaker's honorarium from Pfizer, Ipsen and Novartis and research grants as principal investigator in clinical trial of Novartis. LV, LN. BSS and NRM have received speaker's honorarium and travel support from Novartis and Ipsen. ARO Jr is currently an Ipsen employee. MAC has received speaker's honorarium and consultation fee from Ipsen and Novartis and research grants from Pfizer and Novartis. JA has received speaker's honorarium and consultation fees from Novartis and Ipsen. MDB has received speaker's honorarium, consultation fees and research grants as principal investigator in clinical trial of Novartis and Ipsen. FGD has received speaker's honorarium from Ipsen and consultation fees from Novartis. LK and MRG has received speaker's honorarium from Pfizer, Ipsen and Novartis, consultation fees from Novartis, and research grants as principal or co-investigator in clinical trial of Novartis and Ipsen. MKPH, SRCS and RSJ have no conflict of interest to declare.

\section{REFERENCES}

1. de Vos AM, Ultsch M, Kossiakoff AA. Human growth hormone and extracellular domain of its receptor: crystal structure of the complex. Science. 1992;255(5042):306-12.

2. Brooks AJ, Dai W, O'Mara ML, Abankwa D, Chhabra Y, Pelekanos RA, et al. Mechanism of activation of protein kinase JAK2 by the growth hormone receptor. Science. 2014;344(6185):1249783.

3. Kopchick JJ, Parkinson C, Stevens EC, Trainer PJ. Growth hormone receptor antagonists: discovery, development, and use in patients with acromegaly. Endocr Rev. 2002;23(5):623-46.

4. Tritos NA, Biller BM. Pegvisomant: a growth hormone receptor antagonist used in the treatment of acromegaly. Pituitary. 2017;20(1):129-35.

5. Melmed S. New therapeutic agents for acromegaly. Nat Rev Endocrinol. 2016;12(2):90-8.

6. Giustina A, Arnaldi G, Bogazzi F, Cannavò S, Colao A, De Marinis $\mathrm{L}$, et al. Pegvisomant in acromegaly: an update. J Endocrinol Invest. 2017;40(6):577-89.

7. Brasil. Ministério da Saúde. Protocolo Clínico e Diretrizes Terapêuticas - Acromegalia. 2013. [accessed March 31, 2019]. Available at: http://portalarquivos2.saude.gov.br/images/ pdf/2014/abril/02/pcdt-acromegalia-livro-2013.pdf.

8. Comissão Nacional de Incorporação de Tecnologias no SUS (Conitec). Protocolo Clínico e Diretrizes Terapêuticas da Acromegalia: Relatório de Recomendação. 2018. [accessed March 31, 2019]. Available at: http://conitec.gov.br/images/ Relatorios/2018/Relatorio_Pegvisomanto_Acromegalia.pdf.

9. Massuda A, HoneT, Leles FAG, de Castro MC, Atun R. The Brazilian health system at crossroads: progress, crisis and resilience. BMJ Glob Health. 2018;3(4):e000829.

10. Trainer PJ, Drake WM, Katznelson L, Freda PU, Herman-Bonert V, van der Lely AJ, et al. Treatment of acromegaly with the growth hormone-receptor antagonist pegvisomant. $\mathrm{N}$ Engl J Med. 2000;342(16):1171-7.

11. van der Lely AJ, Hutson RK, Trainer PJ, Besser GM, Barkan AL, Katznelson $L$, et al. Long-term treatment of acromegaly with pegvisomant, a growth hormone receptor antagonist. Lancet. 2001;358(9295):1754-9.

12. Buchfelder M, van der Lely AJ, Biller BMK, Webb SM, Brue T, Strasburger CJ, et al. Long-term treatment with pegvisomant: observations from 2090 acromegaly patients in ACROSTUDY. Eur J Endocrinol. 2018;179(6):419-27.

13. Katznelson L, Laws ER Jr, Melmed S, Molitch ME, Murad MH, Utz A, et al.; Endocrine Society. Acromegaly: an endocrine society clinical practice guideline. J Clin Endocrinol Metab. 2014;99:3933-51.

14. Kasuki L, Machado EO, Ogino LL, Coelho MC, Silva CM, Wildemberg LE, et al. Experience with pegvisomant treatment in acromegaly in a single Brazilian tertiary reference center: efficacy, safety and predictors of response. Arch Endocrinol Metab. 2016;60(5):479-85.

15. Melmed S, Bronstein MD, Chanson P, Klibanski A, Casanueva FF, Wass JAH, et al. A Consensus Statement on acromegaly therapeutic outcomes. Nat Rev Endocrinol. 2018;14(9):552-61.

16. Tritos NA, Chanson $P$, Jimenez C, King D, Jönsson PJ, Klibanski $A$, et al. Effectiveness of first-line pegvisomant monotherapy in acromegaly: an ACROSTUDY analysis. Eur $\mathrm{J}$ Endocrinol. 2017;176(2):213-20.

17. Bolfi F, Neves AF, Boguszewski CL, Nunes-Nogueira VS. Mortality in acromegaly decreased in the last decade: a systematic review and meta-analysis. Eur J Endocrinol. 2018;179(1):59-71.

18. Ben-Shlomo A, Sheppard MC, Stephens JM, Pulgar S, Melmed S. Clinical, quality of life, and economic value of acromegaly disease control. Pituitary. 2011;14(3):284-94.

19. Colao A, Cappabianca P, Caron P, De Menis E, Farrall AJ, Gadelha MR, et al. Octreotide LAR vs. surgery in newly diagnosed patients with acromegaly: a randomized, open-label, multicentre study. Clin Endocrinol (Oxf). 2009;70(5):757-68.

20. Espinosa-de-los-Monteros AL, Gonzalez B, Vargas G, Sosa E, Mercado M. Octreotide LAR treatment of acromegaly in "real life": long-term outcome at a tertiary care center. Pituitary. 2015;18(3):290-6.

21. Alquraini $H$, Del Pilar Schneider $M$, Mirakhur B, Barkan A. Biochemical efficacy of long-acting lanreotide depot/Autogel in patients with acromegaly naïve to somatostatin-receptor ligands: analysis of three multicenter clinical trials. Pituitary. 2018;21(3):283-9.

22. Jallad RS, Musolino NR, Salgado LR, Bronstein MD. Treatment of acromegaly with octreotide-LAR: extensive experience in a Brazilian institution. Clin Endocrinol (Oxf). 2005;63(2):168-75.

23. Gadelha MR, Bronstein MD, Brue T, Coculescu M, Fleseriu M, Guitelman M, et al. Pasireotide versus continued treatment with octreotide or lanreotide in patients with inadequately controlled acromegaly (PAOLA): a randomised, phase 3 trial. Lancet Diabetes Endocrinol. 2014;2(11):875-84.

24. Colao A, Bronstein MD, Freda P, Gu F, Shen CC, Gadelha M, et al. Pasireotide versus octreotide in acromegaly: a head-to-head superiority study. J Clin Endocrinol Metab. 2014;99(3):791-9.

25. Sievers C, Baur DM, Schwanke A, Buchfelder M, Droste M, Mann K, Stalla GK. Prediction of therapy response in acromegalic patients under pegvisomant therapy within the German ACROSTUDY cohort. Pituitary. 2015;18(6):916-23.

26. Franck SE, Korevaar TIM, Petrossians P, Daly AF, Chanson $P$, Jaffrain-Réa $M L$, et al. A multivariable prediction model for pegvisomant dosing: monotherapy and in combination with long-acting somatostatin analogues. Eur $\mathrm{J}$ Endocrinol. 2017;176(4):421-31. 
27. Droste M, Domberg J, Buchfelder M, Mann K, Schwanke A, Stalla G, et al. Therapy of acromegalic patients exacerbated by concomitant type 2 diabetes requires higher pegvisomant doses to normalise IGF1 levels. Eur J Endocrinol. 2014;171(1):59-68.

28. Parkinson C, Burman P, Messig M,Trainer PJ. Gender, body weight, disease activity, and previous radiotherapy influence the response to pegvisomant. J Clin Endocrinol Metab. 2007;92(1):190-5.

29. Neggers SJ, Franck SE, de Rooij FW, Dallenga AH, Poublon RM, Feelders RA, et al. Long-term efficacy and safety of pegvisomant in combination with long-acting somatostatin analogs in acromegaly. J Clin Endocrinol Metab. 2014;99(10):3644-52.

30. Muhammad A, van der Lely AJ, O'Connor RD, Delhanty PJ, Dal J, Dallenga $A H$, et al. What is the efficacy of switching to weekly pegvisomant in acromegaly patients well controlled on combination therapy? Eur J Endocrinol. 2016;174(5):663-7.
31. Freda PU, Gordon MB, Kelepouris N, Jonsson P, KoltowskaHaggstrom M, van der Lely AJ. Long-term treatment with pegvisomant as monotherapy in patients with acromegaly: experience from ACROSTUDY. Endocr Pract. 2015;21(3):264-74.

32. Franck SE, Muhammad A, van der Lely AJ, Neggers SJ. Combined treatment of somatostatin analogues with pegvisomant in acromegaly. Endocrine. 2016;52:206-13.

33. FeolaT, Cozzolino A, Simonelli I, Sbardella E, Pozza C, Giannetta E, et al. Pegvisomant improves Glucose Metabolism in Acromegaly: a meta-analysis of prospective interventional studies. J Clin Endocrinol Metab. 2019;104(7):2892-902.

34. van der Lely AJ, Biller BM, Brue T, Buchfelder M, Ghigo E, Gomez R, et al. Long-term safety of pegvisomant in patients with acromegaly: comprehensive review of 1288 subjects in ACROSTUDY. J Clin Endocrinol Metab. 2012;97(5):1589-97. 